\title{
SPRAY CHARACTERISTICS OPTIMIZATION OF BIODIESEL FUEL IN CONSTANT VOLUME CHAMBER USING MULTI-RESPONSE OPTIMIZATION TECHNIQUE
}

\author{
B. YONESHWAR ${ }^{1 *}$, C. RAJ KISHORE ${ }^{2}$, K. VISHNU ${ }^{3} \&$ P. RAGHU ${ }^{4}$ \\ ${ }^{1,2,3}$ Student, Department of Automobile Engineering, Sri Venkateswara College of Engineering, \\ Pennalur, Sriperumbudur, Tamil Nadu, India \\ ${ }^{4}$ Assistant Professor, Department of Mechanical Engineering, Sri Venkateswara College of Engineering, \\ Pennalur, Sriperumbudur, Tamil Nadu, India
}

\section{ABSTRACT}

This study primarily focuses on optimizing the spray characteristics of biodiesel fuel in a spray chamber. Three factors have been considered; fuel injection pressure, number of nozzle holes and fuel blends. To achieve this objective, these were chosen as the factors (injection pressure, number of nozzle holes, fuel blends). Three levels were chosen as the response variable namely, Spray penetration length $(S)$, Spray angle $(\theta)$ and Sauter mean diameter (SMD). These investigaten were done with the aid of Taguchi full factorial array method.To calculate the response variables, theMulti Response Signal to Noise Ratio (MRSN) technique was used. To find optimum combination level of factors, the Taguchi's parametric design were exploited.

KEYWORDS: Taguchi, Spray Penetration Length, Spray Angle, Sauter Mean Diameter, Injection Pressure \& Number of Nozzle Holes

Received: May 17, 2019; Accepted: Jun 07, 2019; Published: Jul 18, 2019; Paper Id.: IJMPERDAUG2019116

\section{INTRODUCTION}

The spray characteristics of tested fuel greatly determining factor for the emissions from compression ignition engines. Spray characteristics play a vital role in air/fuel mixture and burning in a petrol or diesel engine (internal combustion engine). It is primary to optimize the spray conditions in order to reduce pollution. Taguchi full factorial method is engaged to optimize the Spray characteristics. The Taguchi design of experiments is broadly utilized to influence the parameter content or scene, necessary to obtain the desired output. Literature review was done on Taguchi's approach in application in engine parameters.

The causal factor of the control variant, piston to head clearance volume, injection timing, area of the spray nozzle hole and the load torque on NOx emissions and brake specific fuel consumption (BSFC) of a DI single cylinder diesel engine was investigated. The value of these regular factors on the consequence variables were known by the Taguchi method of DOE. Analysis method is used to stipulate their level of signification in the form of proportion attempt to the total activity of the response variables [1].

To analyze the combustion characteristics of biodiesel blend as a fuel diesel engine, they carried out a research work [2]. In operation with biodiesel blend, the cylinder pressure was equalled with that of diesel fuel. 
It was observed that the delay period and the maximum rate of pressure rise for blend were lower berth than diesel fuel. The happening of maximum heat release rate advanced for biodiesel blend with small magnitude when compared to diesel fuel.

A numerical and experimental analysis of injection process using biodiesel-diesel blends with the purpose to bring down engine harmful emissions was studied [3]. The profound fuel was biodiesel from rapeseed oil and its blends with diesel. The effect discovered that, while keeping engine performance inside satisfactory limits, harmful emissions can be reduced by set appropriately by pump injection timing.

Performance Evaluation of Biodiesel Engine Using Optimization Techniques was carried out [4]. The experimentation was planned using a statistical tool known as DOE based on Taguchi methods. Four factors such as compression ratio, injection pressure, load, blend proportions were varying at three levels, and the consequencearespecific fuel consumption, brake power, brake thermal efficiency. Consequence of conformation tests entertains good agreement with foreseen measure.

The response surface methodology was used to optimize the manufacture process of second generation biodiesel from Australian native stone fruit by an alkali catalysed trans-esterification process [5]. This process status was performed with changeable three factors, each at three different levels. Methanol, oil molar ratio, catalyst concentration and reaction temperature were the input constituent in the optimisation process, while biodiesel output was the key model output.

This study analyses the trans-esterification of vegetable oilcatalysed with potassium hydroxide (KOH). By evaluating with ASTM standardised, biodiesel make were of good prime. Waste cooking oils constitute ready feedstock for high volume, good quality and property production of biodiesel as well as a pragmatic means of destructing the pollution, resulting from the wholesale feat of waste oils, ordinary to both household and industrial purposes [6].

Biodiesel is an alternate inexhaustible fuel, which is successful by using biomass origin. Its chemical science attributes are approximate to those of the crude oil (diesel fuel). The primary purpose of this research activity is to optimise the action factor, viz. the methanol-to-oil molar ratio, catalyst concentration, reaction time and reaction temperature for biodiesel production. The Taguchi robust arrangement formulation was used with an orthogonal array of L9 to examine the determinant of process element on execution factor [7]. Spray penetration length is characterized as the largest size, calculated along the spray axis.The spray angle is formed, as the angle produced by two straight lines that start from the exit of the nozzle orifice and tangent to the spray boundary. The atomization prime of a liquid spray can be computed by the medium diameter of the droplets.

\section{EXPERIMENTAL SETUP}

Figure 1 represents the experimental setup. This setup consists of a spray chamber $(200 \times 90 \times 220 \mathrm{~mm})$, fuel injection system and a digital camera. Here, the spray characteristics were ascertained from a spray chamber, alongside with a normal lighting conditions and Fuel injection system. The spray chamber is made of glass. The fuel injection system consists of an electric motor (0.25hp), amechanical fuel pump,three different fuel injectors which have various number of nozzle holes namely one,three and five hole nozzles having different hole diameters at three different injection pressures 180,200 and 220 bar. The spray videos were recorded at the native declaration of the digital camera. Later, the spray images were captured from it. Fuels were Diesel, Corn Oil Methyl Ester (COME) and Blend (CB20). The snapshots of the sprays were analysed using ImageJ software.The spray parameters like spray penetration length and spray angle were 
determined using the Image J software. By using the formula, S.M.D values were found.Table.1 gives the diameters for the respective injector nozzle [8].

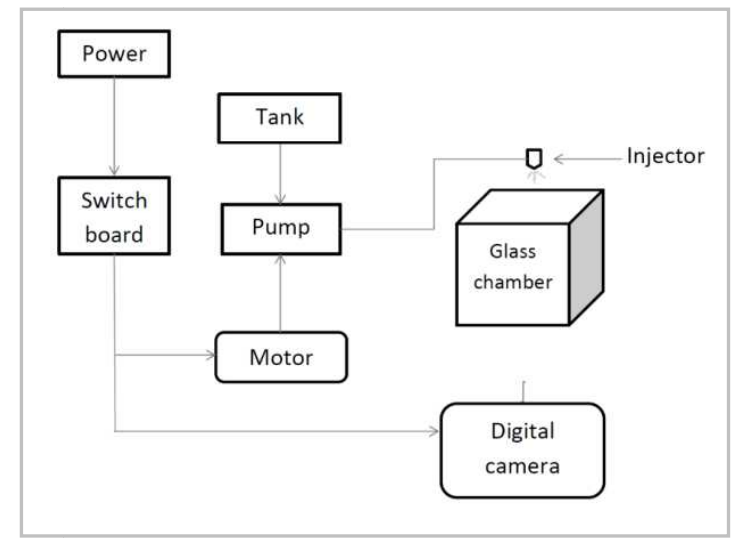

Figure 1: The Experimental Setup for Spray Measurement

Table 1: Diameter of Nozzle Holes

\begin{tabular}{|c|c|}
\hline Number of Nozzle Holes & Diameter of Nozzle Holes \\
\hline 1 & $0.32 \mathrm{~mm}$ \\
\hline 3 & $0.25 \mathrm{~mm}$ \\
\hline 5 & $0.23 \mathrm{~mm}$ \\
\hline
\end{tabular}

\section{SELECTION OF FACTORS}

The factors that are selected are not distinct but can be measurable.To find the influence of fuels, number of nozzle holes and fuel injection pressure on spray parameter such as SMD,spray penetration length and spray angle quantities have to be chosen from a minimal values to maximal values. The lower limit and upper limit values are selected for the current work from earlier research work, which was conducted with each of the above factors. The Table 2 for each of the above element (factors), three levels was selected to analyse the selected factor on the selected objective.

Table 2: Option of Element

\begin{tabular}{|c|l|c|c|c|}
\hline \multirow{2}{*}{$\begin{array}{c}\text { Factor } \\
\text { No }\end{array}$} & \multicolumn{1}{|c|}{$\begin{array}{c}\text { Factors Influencing } \\
\text { the Objective }\end{array}$} & \multicolumn{3}{|c|}{ Levels of Factors } \\
\cline { 3 - 5 } & Fuels & $\mathbf{1}$ & $\mathbf{2}$ & $\mathbf{3}$ \\
\hline 1 & $\begin{array}{l}\text { Injection } \\
\text { pressure, bar }\end{array}$ & 180 & 200 & 220 \\
\hline 3 & Number of nozzle holes & 1 & 3 & 5 \\
\hline
\end{tabular}

\section{THE EXPERIMENTAL DESIGN}

The experimental design used is a full factoriall design, for each of the element three levels are chosen, thus the trials to be carried outwill be $3^{3}=27$. The degrees of freedom for $\mathrm{L}_{27} 27(3 \times 3 \times 3)$ are 26 (number of experiments -1$)$. The Table 3 shows the choice of factorial experimental matrix.

\section{ANALYSIS OF DATA}

The response of variables are spray penetration length, spray angle, and SMD of the problem was carried out for achieving the result.The response acquired for all of the trials at various situation were examined. For the trail analysis, 
mean values of the responses at different operating conditions were recorded. To optimize the combination of the level of the above elements for the problem, the MRSN is used [8].

The steps followed in the optimization process are explained beneath as the Loss Function.

\section{LOSS FUNCTION}

Loss Function can be in use to determine the differencefor the empirical and the desirable quantity. To each one of the effectfunction, the respective failure (loss) function can be explicit as taken for calculation. The smaller it is better principle to minimize the spray penetration length and SMD. For spray angle, larger the better principle is considered to maximize it, using Taguchi technique for the response factors, which was considered [8] [9].

For the spray penetrationlength and SMD, the lower the better value was considered

$$
L_{i j}=\frac{1}{n} \sum_{k=1}^{n} y_{i j k}^{2}
$$

For the Spray angle, highest value was considered

$$
L_{i j}=\frac{1}{n} \sum_{k=1}^{n} \frac{1}{y^{2} i j k}
$$

Then is the amount of recurrent values, $L_{i j}$ is the loss function of the ith outcome variant in the $j^{\text {th }}$ experimental values at the $\mathrm{k}^{\text {th }}$ trial.

\section{THE LOSS FUNCTION NORMALIZING}

The calculated units of the output variant are not same; the loss function was normalized forone and zero. Theloss function Normalization was through with as

For the Spray penetration length and SMD, the lowest value was considered as

$$
S_{i j}=\frac{\min L_{i j}}{L_{i j}}
$$

For the Spray angle, the highest value was considered

$$
S_{i j}=\frac{L_{i j}}{\max L_{i j}}
$$

The loss function normalized was given as by $\mathrm{S}_{\mathrm{ij}}$.

\section{Distributionof Weighting Factor}

In the instance of MRSN, the comparative significance to each outcome variable on the situated subjective alteration with regard to difference will be fixed by assignment of correct distribution of weighting factor. For all the loss function normalizing, the whole loss function $\left(\mathrm{T}_{\mathrm{Lf}}\right)$ can be stated as

$$
T L_{i j}=\sum_{k=1}^{m} w_{i} s_{i j}
$$

$\mathrm{w}_{\mathrm{i}}$ is the weighting factor.In this optimization process, with three output variant, for the sequence $0.8,0.1$ and 0.1 , the value of first output variant is very higher when compared to the another two. 


\section{MRSN}

The MRSN ratio has to be expression by using

$$
M R S N=-\log \left(T L_{j}\right)
$$

Optimal level of combination for the obtained MRSN ratio with the assigned weighting factor was determined by side by side parametric design.

\section{RESULT AND DISCUSSION}

\section{MRSN Quantitative Relation}

Table 3 shows the MRSN quantitative relationfor the experimentation transition for the weighting factor determination $\mathrm{w}_{1}=0.8, \mathrm{w}_{2}=0.1$, and $\mathrm{w}_{3}=0.1$. It can be determined that, looking into the number $(3,3,1)$ is the foremost sequence among the 27 combination.

\begin{tabular}{|c|c|c|c|c|c|c|c|c|c|c|c|c|c|c|}
\hline \multirow{3}{*}{$\begin{array}{c}\text { Exp } \\
\text { No } \\
1 \\
\end{array}$} & \multirow{2}{*}{\multicolumn{3}{|c|}{$\begin{array}{c}\text { Full } \\
\text { Factorial } \\
\text { Design }\end{array}$}} & \multicolumn{3}{|c|}{ Loss Function (Lij) } & \multirow{2}{*}{\multicolumn{3}{|c|}{$\begin{array}{c}\text { Normalisation } \\
\text { (Sij) }\end{array}$}} & \multirow{2}{*}{\multicolumn{3}{|c|}{ Weighting Factor }} & \multirow{3}{*}{$\begin{array}{c}\begin{array}{c}\text { Total Loss } \\
\text { Function (Tlij) }\end{array} \\
0.62\end{array}$} & \multirow{3}{*}{$\begin{array}{c}\text { MRSN } \\
\text { Ratio }\end{array}$} \\
\hline & & & & \multirow{2}{*}{$\begin{array}{c}\mathbf{S} \\
33760.4\end{array}$} & \multirow{2}{*}{$\begin{array}{c}\boldsymbol{\theta} \\
0.05\end{array}$} & \multirow{2}{*}{$\begin{array}{l}\text { S.M.D } \\
166.08\end{array}$} & & & & & & & & \\
\hline & 1 & 1 & 1 & & & & 0.64 & 0.71 & 0.37 & 0.51 & 0.07 & 0.04 & & \\
\hline 2 & 1 & 1 & 2 & 28612.4 & 0.04 & 91.84 & 0.75 & 0.55 & 0.67 & 0.6 & 0.06 & 0.07 & 0.73 & 1.39 \\
\hline 3 & 1 & 1 & 3 & 21776.9 & 0.03 & 75.18 & 0.99 & 0.43 & 0.82 & 0.79 & 0.04 & 0.08 & 0.92 & 0.37 \\
\hline 4 & 1 & 2 & 1 & 36299.8 & 0.06 & 149.39 & 0.59 & 0.84 & 0.41 & 0.48 & 0.08 & 0.04 & 0.6 & 2.21 \\
\hline 5 & 1 & 2 & 2 & 29245.1 & 0.05 & 82.61 & 0.74 & 0.63 & 0.74 & 0.59 & 0.06 & 0.07 & 0.73 & 1.38 \\
\hline 6 & 1 & 2 & 3 & 24611.3 & 0.04 & 67.62 & 0.88 & 0.5 & 0.91 & 0.7 & 0.05 & 0.09 & 0.84 & 0.74 \\
\hline 7 & 1 & 3 & 1 & 40645.8 & 0.08 & 135.75 & 0.53 & 1 & 0.45 & 0.42 & 0.1 & 0.05 & 0.57 & 2.44 \\
\hline 8 & 1 & 3 & 2 & 30539.3 & 0.05 & 75.06 & 0.71 & 0.7 & 0.82 & 0.57 & 0.07 & 0.08 & 0.72 & 1.44 \\
\hline 9 & 1 & 3 & 3 & 28455 & 0.04 & 61.46 & 0.76 & 0.56 & 1 & 0.61 & 0.06 & 0.1 & 0.76 & 1.17 \\
\hline 10 & 2 & 1 & 1 & 32490.1 & 0.05 & 171.66 & 0.66 & 0.71 & 0.36 & 0.53 & 0.07 & 0.04 & 0.64 & 1.95 \\
\hline 11 & 2 & 1 & 2 & 26308.5 & 0.05 & 94.92 & 0.82 & 0.66 & 0.65 & 0.66 & 0.07 & 0.06 & 0.79 & 1.04 \\
\hline 12 & 2 & 1 & 3 & 21591.4 & 0.04 & 77.71 & 1 & 0.53 & 0.79 & 0.8 & 0.05 & 0.08 & 0.93 & 0.31 \\
\hline 13 & 2 & 2 & 1 & 41922.6 & 0.06 & 154.41 & 0.52 & 0.84 & 0.4 & 0.41 & 0.08 & 0.04 & 0.54 & 2.71 \\
\hline 14 & 2 & 2 & 2 & 35883.7 & 0.05 & 85.38 & 0.6 & 0.72 & 0.72 & 0.48 & 0.07 & 0.07 & 0.63 & 2.04 \\
\hline 15 & 2 & 2 & 3 & 28009.4 & 0.05 & 69.9 & 0.77 & 0.64 & 0.88 & 0.62 & 0.06 & 0.09 & 0.77 & 1.14 \\
\hline 16 & 2 & 3 & 1 & 52757.5 & 0.07 & 140.31 & 0.41 & 0.96 & 0.44 & 0.33 & 0.1 & 0.04 & 0.47 & 3.31 \\
\hline 17 & 2 & 3 & 2 & 37091.7 & 0.06 & 77.58 & 0.58 & 0.79 & 0.79 & 0.47 & 0.08 & 0.08 & 0.62 & 2.05 \\
\hline 18 & 2 & 3 & 3 & 30969 & 0.05 & 63.51 & 0.7 & 0.72 & 0.97 & 0.56 & 0.07 & 0.1 & 0.73 & 1.39 \\
\hline 19 & 3 & 1 & 1 & 36400.8 & 0.04 & 169.56 & 0.59 & 0.52 & 0.36 & 0.47 & 0.05 & 0.04 & 0.56 & 2.5 \\
\hline 20 & 3 & 1 & 2 & 29873.7 & 0.04 & 93.76 & 0.72 & 0.47 & 0.66 & 0.58 & 0.05 & 0.07 & 0.69 & 1.6 \\
\hline 21 & 3 & 1 & 3 & 25792.4 & 0.03 & 76.76 & 0.84 & 0.42 & 0.8 & 0.67 & 0.04 & 0.08 & 0.79 & 1.02 \\
\hline 22 & 3 & 2 & 1 & 44327.1 & 0.05 & 152.52 & 0.49 & 0.61 & 0.4 & 0.39 & 0.06 & 0.04 & 0.49 & 3.09 \\
\hline 23 & 3 & 2 & 2 & 35178.8 & 0.04 & 84.34 & 0.61 & 0.55 & 0.73 & 0.49 & 0.06 & 0.07 & 0.62 & 2.08 \\
\hline 24 & 3 & 2 & 3 & 29549.6 & 0.03 & 69.04 & 0.73 & 0.46 & 0.89 & 0.58 & 0.05 & 0.09 & 0.72 & 1.43 \\
\hline 25 & 3 & 3 & 1 & 52959.8 & 0.05 & 138.59 & 0.41 & 0.67 & 0.44 & 0.33 & 0.07 & 0.04 & 0.44 & 3.6 \\
\hline 26 & 3 & 3 & 2 & 43180.8 & 0.05 & 76.64 & 0.5 & 0.62 & 0.8 & 0.4 & 0.06 & 0.08 & 0.54 & 2.66 \\
\hline 27 & 3 & 3 & 3 & 38149.9 & 0.04 & 62.74 & 0.57 & 0.52 & 0.98 & 0.45 & 0.05 & 0.1 & 0.6 & 2.20 \\
\hline
\end{tabular}




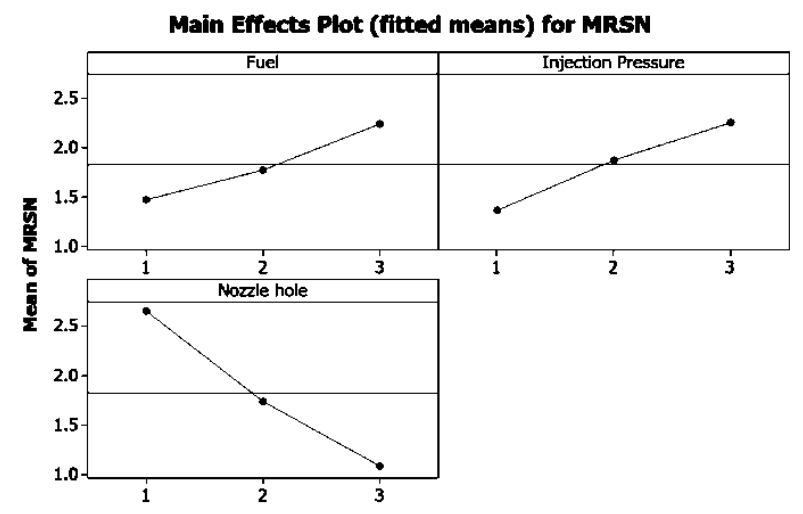

Figure 2: The Main Effect Plot for MRSN Values

\section{THE CONSEQUENCE VARIABLES AT OPTIMIZED CONDITION}

The attained optimal combination level and optimal combination for the response variable have been compared with the response variables of the experimentation that had been conduit with the normal operational state(Fuel as CB20, Injection pressure as 220 bar, nozzle as Single hole nozzle). It can be observed that spray angle is enhanced and spray penetration length and SMD reduced accordingly as an outcome of this related effect. The thirdvaluesof injection pressure and fuels and first values of number of nozzle hole was the optimal sequence for get down for SMD, spray penetration and higher spray angle.

\section{CONCLUSIONS}

The study employs DOE and factorial experimental matrix for spray characteristics of fuels, with respect to the number of nozzles at diverse injection pressures, and to analyze the combined effect of chosen factors and variables with the minimum number of trail. The MRSN quantities were fed into Minitab 14, and subsequently, DOE was performed. s The fitted plots were done for the MRSN values, which indicated the same i.e. at third level for fuel (CB20), at third level of injection pressure (220 bar) and at first level for number of nozzle (single hole nozzle). Time and money spent was decreased as a result of employing the Taguchi's DOE method.

\section{ACKNOWLEDGEMENT}

The authors thank the management of Sri Venkateswara College of Engineering for giving us with the essential experimental setup, to execute this investigation work.

\section{REFERENCES}

1. Vincent H. Wilson and Udayakumar, "Journal of the Brazilian Society of Mechanical Sciences and Engineering" 34(4):423-428, October 2012.

2. S. Saravanan, G. Nagarajan, G. Lakshmi Narayana Rao, S. Sampath “Combustion characteristics of a stationary diesel engine fuelled with a blend of crude rice bran oil methyl ester and diesel”, Energy, 35, pp. 94-100,2010

3. Breda, Kegl 2006, "Numerical analysis of injection characteristics using biodiesel fuel”. Fuel. 2006. http://dx.doi.org/10.1016/j.

4. Devandra Reddy Murali C Suresh D,Performance Evaluation of a Biodiesel Engine Using Optimization Techniques, International Journal of Engineering Research And Advanced Technology, 3122 Vol.3 (7) July-2017, 
5. Mohammad Anwar, Mohammad G. Rasul,NanjappaAshwath andMdMofijurRahman, Optimisation of Second-Generation Biodiesel Production from Australian Native Stone Fruit Oil Using Response Surface Method, 2018

6. Ayodele A. Ayoola, K.F. Hymore and C.A. Omonhinmin, Optimization of Biodiesel Production from Selected Waste Oils Using Response Surface Methodology, Biotechnology, Volume 16 (1): 1-9, 2017

7. Agarana, M. C., Bishop, S. A., \& Odetunmibi, O. (2014). Optimization of banks loan portfolio management using goal programming technique. International Journal of Research in Applied Natural and Social Sciences (IMPACT: IJRANSS), 2(8), 43-52.

8. N. Kumar,S. K. Mohapatra,S. S. Ragit,K. Kundu,R. Karmakar, ptimization of safflower oil transesterification using the Taguchi approach, November 2017, Volume 14, Issue 4, pp 798-805

9. P. Raghu, N. Nallusamy, "Spray Characteristics of Biodiesel Fuel in Constant Volume Chamber using Multi-response Optimization Technique”, Journal of Thermal Science Vol.25, No.6 (2016) 581-588.

10. PJ.Rose, Taguchi techniques for quality engineering McGraw-Hill Book Company, USA, 1998. 
